\title{
Microsimulation of Health Claim Expenditure with Markov Transition Probabilities: Optimistic, Mean, and Pessimistic Scenarios
}

Zarul Khaliff Kamal ${ }^{*}$, Noriszura Ismail ${ }^{2}$, Shamshimah Samsuddin ${ }^{3}$ and Ros Idayuwati Alaudin 4

\author{
${ }^{1,2}$ School of Mathematical Sciences, Faculty of Science and Technology, Universiti \\ Kebangsaan Malaysia, 43600 Bangi, Selangor, Malaysia \\ ${ }^{3}$ Centre for Actuarial Studies, Faculty of Computer and Mathematical Sciences, Universiti \\ Teknologi MARA, 40450 Shah Alam, Selangor, Malaysia \\ ${ }^{4}$ School of Quantitative Sciences, College of Arts and Sciences, Universiti Utara \\ Malaysia, 06010 UUM, Sintok, Kedah, Malaysia.
}

\begin{abstract}
Over the past few years, health expenditure from the public sector agencies and private sector agencies has been increasing and this situation may lead to economic burden. The objective of this study is to estimate the health claim expenditure (HCE) among Social Security Organization (SOCSO) contributors using Markov transition probabilities based on health states namely healthy $(\mathrm{H})$, temporary disabled (TD), partial permanently disabled (PPD), and death (D) using previous claim data from 2009 to 2014. This study simulates three scenarios of claims: optimistic, pessimistic, and mean. In addition, the quality of life loss among contributors is also computed using Quality Adjusted Life Year (QALY) indicator. The results indicate that the HCE for male contributors are higher than that of the female contributors for all scenarios. Meanwhile, the results of QALY show that the male contributors bear more severe injuries and illnesses compared to female contributors.
\end{abstract}

Keywords: claim amount, claim cost, discounted cost, health claim expenditure, Markov transition probabilities.

\section{INTRODUCTION}

In Malaysia, health expenditure is financed by two agencies: public sector agencies and private sector agencies. The public sector agencies consist of the federal government, state government, and local authorities. Meanwhile, the private sector agencies comprise Employees Provident Fund (EPF), Social Security Organization (SOCSO), private household out of pocket (OOP), and nonprofit institutions serving households. Both agencies recorded a substantial amount of spending, as the health expenditure from public sector agencies increased from RM22694 million in 2013 to RM25814 million in 2014, while the health expenditure from private sector agencies rose from RM21652 million to RM23917 million in the same period (Zainuddin, 2014). This national expenditure is expected to increase in line with the demographic shift due to expanding elderly population. In addition, the future health expenditure is also uncertain and thus, mathematical modelling is needed to project future expenditure.

Social Security Organization (SOCSO) provides protection with coverage of benefits for private employees that receive RM400o or less per month, as well as for contractual and temporary civil servants. SOCSO offers three main schemes: Employment Injury Scheme (EIS), Invalidity Schemes (IS), and Self-Employed Employment Injury Scheme. In general, EIS offers medical benefits, temporary and permanent disablement benefits, dependents' benefits, and vocational rehabilitation. Meanwhile, IS provides benefits for incurable diseases, invalidity pension, invalidity grant, funeral benefits and many more. As for the Self- 
Employed Employment Injury Scheme, the benefits are similar to the EIS, however this scheme only caters to taxi drivers.

The aim of this study is to examine the health claim expenditure (HCE) among SOCSO contributors under the EIS scheme using Markov transition probabilities based on previous claim from 2009 to 2014. This study introduces several health states, comprising healthy $(\mathrm{H})$, temporary disabled (TD), partial permanently disabled (PPD), and death (D). In addition, this study simulates three claim scenarios, which includes optimistic, pessimistic, and mean claim. The microsimulation models used in this study are based on several predetermined variable including average interest rate, maximum and minimum daily claims amount, utility weight, and some other related variables. In addition, we also aim to measure the loss of quality of life due to sickness using Quality Adjusted Living Year (QALY). The QALY incorporates both the quality and length of life of a patient. Consequently, we will be able to compare the quality of life and claim cost scenarios among sick employees in EIS, which were lacking in the previous studies on this topic. This study contributes in terms of two main elements: i) to estimate the future cost of Employment Injury Scheme (EIS) based on Markov transition probabilities using microsimulation model, ii) to examine the liability of the sickness using QALY for SOCSO contributors, and iii) to compare the quality of life and claim cost frequency among sick employees in EIS.

In the current literatures, there have been numerous microsimulation models developed for estimating future health conditions and diseases. Van Ballegooijen et al. (2011) utilized three microsimulation models, namely Microsimulation Screening Analysis (MISCAN), Colorectal Cancer Simulated Population model for Incidence and Natural history (CRC-SPIN) and Simulation Model of Colorectal Cancer (SimCRC) in estimating the mortality rate among early detected colorectal cancer patients. They found that CRC-SPIN and SimCRC produced more consistent mortality rate than MISCAN. These microsimulation models used detailed information on diseases starting from the formation of tumor to the time of death in order to have better estimation of future health condition of a patient. However, no underlying medical costs of diseases and treatments were enforced in the models. Hennessy et al.(2015) developed Population Health Model (POHEM) to determine the future quality of life and health cost among Canadians, based on the individual state of disease, risk factor, and other factors related to health, instead of simply projecting the future health state of a patient. However, POHEM needs a particular information of a patient such as his/her Body Mass Index (BMI), level of hypertension and diabetes, and some other health details that can only be obtained through a comprehensive interview.

As a general rule, the utility of 1 is assigned when an individual is in perfect health and utility of $o$ when an individual dies (Rongen et. al., 2016, Krijkamp et. al., 2018, Roudijk et. al., 2018). However, for the case of an individual who is not in perfect health condition, the value of utility used varies depending on how serious the diseases are. For instance, Roudijk et. al., (2018) utilized utility value of 0.7 for mild sickness and utility value of 0.4 for moderate sickness. Meanwhile, Rongen et. al., (2016) assigned a utility value of 0.84 for individuals who were successful in the total knee replacement surgery, and a utility value of 0.53 for individuals who failed in the knee replacement surgery. These utility values were estimated by Mather et. al., (2013). The dissimilarity of utility values come from different derivation method. Whitehead and Ali (2010) conducted questionnaire survey of the individuals, later recorded the responses based on the levels of sickness: no problems, some problems, and severe problems. Rongen et. al., (2016) utilized randomized controlled trial by assigning individuals into control and experimental groups to reduce bias from the questionnaires. The utility value of QALY was assigned based on the quality of life of patients reported by the experimental group. Obviously, a study needs an intensive data on the progress of sickness among patients to get the value of utility.

\section{MATERIALS AND METHODS}

Table 1 shows a set of deterministic parameters used in simulating HCE among SOCSO contributors under EIS. We carried out a simulation of 100000 individuals, male and female with the number of discrete cycles of 20 years and each cycle length of one year. A sample of 100000 individuals is selected to ensure the output is large enough to approach and converge the true value. Additionally, we implement 20 years discrete cycles because this period is adequate for a person to recover from temporary or permanent partial disability state to healthy state and vice versa (Taş et. al., 2012). 
Table 1: Summary of deterministic parameters used in the microsimulation of health claim cost in EIS

\begin{tabular}{|c|c|c|}
\hline $\begin{array}{l}\text { Parameter } \\
\text { Description }\end{array}$ & Value & Source \\
\hline $\begin{array}{l}\text { Number of } \\
\text { simulated } \\
\text { individuals }\end{array}$ & 100000 & - \\
\hline $\begin{array}{l}\text { Number of } \\
\text { discrete cycle }\end{array}$ & 20 years & $\begin{array}{l}\text { Taş et. al., } \\
(2012)\end{array}$ \\
\hline Cycle length & 1 year & $\begin{array}{l}\text { Rongen et. al., } \\
\text { (2016) }\end{array}$ \\
\hline $\begin{array}{l}\text { Markov } \\
\text { states }\end{array}$ & $\begin{array}{l}\text { H: health } \\
\text { TD: Temporary Disabled } \\
\text { PPD: Partial Permanently } \\
\text { Disabled } \\
\text { D: Death }\end{array}$ & $\begin{array}{l}\text { Samsuddin et. } \\
\text { al., (2018) }\end{array}$ \\
\hline $\begin{array}{l}\text { Average } \\
\text { interest rate } \\
\text { (Jan 2017 to } \\
\text { June 2018) }\end{array}$ & 0.03 & BNM \\
\hline $\begin{array}{l}\text { Pessimistic } \\
\text { claim }\end{array}$ & $\begin{array}{l}\text { H: RM o.oo } \\
\text { TD: RM } 5400 \\
\text { PPD: RM } 10800\end{array}$ & SOCSO \\
\hline Mean claim & $\begin{array}{l}\text { H: RM o.oo } \\
\text { TD: RM } 12179.70 \\
\text { PPD: RM } 26730\end{array}$ & SOCSO \\
\hline $\begin{array}{l}\text { Optimistic } \\
\text { claim }\end{array}$ & $\begin{array}{l}\text { H: RM o.0o } \\
\text { TD: RM } 18959.40 \\
\text { PPD: RM } 42660\end{array}$ & SOCSO \\
\hline Utility weight & $\begin{array}{l}\text { H: } 1.00 \\
\text { TD: } 0.7 \\
\text { PPD: } 0.4\end{array}$ & $\begin{array}{l}\text { Roudijk et. al., } \\
\text { (2018) }\end{array}$ \\
\hline
\end{tabular}

Based on the EIS claim data from SOCSO, there are four health states: healthy $(\mathrm{H})$, temporary disabled (TD), partial permanently disabled (PPD), and death (D). A person is healthy when he/she has no claim submitted in a year. According to the Employees' Social Security Act 1969, a patient is considered a temporarily disabled patient if he/she has curable physical injuries or illness in a short period of time (days, weeks, and months). On the other hand, partial permanently disabled is defined as a patient with physical injuries or illness that are incurable that interferes with normal activities in the long term (years). In terms of cycle length, the micro data on daily sick claim are not available to the public. Consequently, we assumed contributors with TD maximizing 180 -day claim in a year, and those with PPD maximizing 360-day claim. Therefore, a cycle length of one year is selected.

For the amount of expected claim, the total optimistic claims for TD and PPD are RM18959.40 and RM42660, respectively. The values are computed based on daily claims, which are RM105.33 for TD and RM118.50 for PPD. Meanwhile, for pessimistic claims, the total for TD and PPD are expected to be RM5400 and RM1080o respectively. These values are derived from minimum claim payment for TD and PPD, which is RM30 per day multiplied with the maximum number of leave. In other words, the optimistic claim indicates the highest amount that an employee can claim from EIS. Meanwhile, pessimistic claim indicates the lowest amount that an employee can claim from EIS.

We also assumed that all workers have good health condition at start of work as it is a requirement before accepting for the employment. Consequently, health cost is equal to zero, and QALY is equal to 1, indicating perfect health. Based on health state at Time 1, the future health state (Time 2 onwards until Time 20) will be determined by the microsimulation process. The health cost and QALY are followed afterwards depending on health state.

We also assumed that all workers are in good health condition at the start of work as it is a requirement before accepting their employment. Consequently, health cost is equal to zero, and QALY is equal to 1 , indicating perfect health. Based on health state at Time 1, the future health state (Time 2 onwards until Time 20) will be determined by the microsimulation process. The health cost and QALY are followed afterwards depending on the health state.

The total discounted HCE will be calculated using average discount rate from January 2017 to June 2018. Technically, the formula is utilized as follows:

$$
D_{H C E}=\sum_{n=0}^{19}\left(H C E_{i} \times \frac{1}{\left(1+d_{r}\right)^{n}}\right)
$$

where $D_{H C E}$ is the total discounted HCE, $n$ is the number of discrete cycle, $H C E_{i}$ is the $\mathrm{HCE}$ for individual $i$, where $i=$ $1,2,3, \ldots, 100000$, and $d_{r}$ is the discount rate at $3 \%$. The average of HCE for both male and female at each cycle is obtained by computing the mean discounted HCE using the formula as follows: 


$$
D_{\overline{H C E}}=\frac{\sum_{n=0}^{19} D_{H C E_{i n}}}{100000}
$$

where $D_{\overline{H C E}}$ is the mean discounted HCE and $D_{H C E_{i}}$ is the total discounted HCE at each cycle for $i=1,2,3, \ldots, 100000$.

We first have to specify the value of the utility weight that requires the details on progress of sickness for a specified period of implementing QALY. However, due to the unavailability of data, we apply the existing utility values from the previous studies that are appropriate to our study, as suggested by Ara and Wailoo (2012). From the previous researches, we use a utility value of 1 for perfect health within one year as was used by Rongen et al. (2016). Meanwhile, we assign a utility value of 0.7 for TP and 0.4 for PD, similar to the value used by Roudijk et al. (2018). The model for computing QALY is as follows:

$$
Q=\sum_{i=0}^{19} C_{i} \cdot u t_{i}
$$

where $Q$ is QALY, $u t_{i}$ is the utility value for $i$ equals to $\mathrm{H}$, TD, PPD, and D. Meanwhile, $C_{i}$ represents the cycle length. The average QALY after 20 cycles is computed using the formula as follows:

$$
\overline{Q A L Y}=\frac{\sum_{n=0}^{19} Q A L Y_{i_{n}}}{100000}
$$

where $\overline{Q A L Y}$ is the mean of QALY and $Q A L Y_{i}$ is the total number of QALY at each cycle for $i=1,2,3, \ldots, 100000$. The transition probabilities between H, TD, PPD, and D states are referred from Samsuddin and Ismail (2018) because the data used in their study is large enough to describe the real situation where a total of 212426 employees were recorded at the beginning of the period. Furthermore, they used quite recent dataset, which are claims reported to SOCSO from 2009 to 2014.

\section{RESULTS AND DISCUSSIONS}

The HCE is used as a platform for computing needs throughout the working years. In addition, the HCE can be one of the sources of the three-legged stool of retirement incomes. Meanwhile, the average $\mathrm{HCE}$ is used as an instrument to compute the mean of possible claim in 20 years. The transition probabilities for the HCE is as shown in Table 3 and Table 4 . Since every person is assumed to be in perfect health at the start of microsimulation, they can stay healthy in the next period, or move to state TD or state PPD, or move straight to state D. A person in state PPD can recover to either state TD or directly jump to state $\mathrm{H}$. In addition, a person in state PPD is more likely to recover to state $\mathrm{H}$ than staying in state PPD or moving to state TD. Meanwhile, a person in state $\mathrm{H}$ is more likely to move to state D (for both male and female), compared to other states (H, TD, and PPD).

Table 3: Transition probabilities states for EIS from 2009 -

\begin{tabular}{lllll}
\multicolumn{5}{c}{2013} \\
\hline & Male & PPD & D \\
H & 0.7267 & 0.1906 & 0.0773 & 0.0054 \\
TD & 0.9451 & 0.0435 & 0.0107 & 0.0006 \\
PPD & 0.9548 & 0.0225 & 0.0223 & 0.0004 \\
D & 0.0000 & 0.0000 & 0.0000 & 1.0000 \\
\hline
\end{tabular}

Table 4: Transition probabilities states for EIS from 2009 -

\begin{tabular}{lllll}
\multicolumn{5}{c}{2013} \\
\hline & Female & TD & PPD & D \\
H & 0.7325 & 0.2017 & 0.0634 & 0.0024 \\
TD & 0.9734 & 0.0218 & 0.0048 & 0.0001 \\
PPD & 0.9692 & 0.0178 & 0.0128 & 0.0002 \\
D & 0.0000 & 0.0000 & 0.0000 & 1.0000 \\
\hline
\end{tabular}

Table 5 shows the optimistic, mean, and pessimistic HCE for both male and female together with the mean of QALY. The stochastic characteristic of microsimulation model influences the heterogeneity of the claim cost in Table 5 . Overall, the mean of total HCE for all scenarios for male contributors are higher than that of female contributors. With respect to the pessimistic scenario, the claim amount of male contributors is RM 21,095.80 (RM1,054.80 per year), while the claim amount of female contributors is RM20,475 (RM1,023.75 per year). Meanwhile, the mean claim amount is RM 49,537.53 (RM2,476.90 per year) for male and RM47,917.80 (RM2,395.90 per year) for female. With regard to the optimistic scenario, the claim amount of male contributors is RM77929.76 (RM3896.50 per year), while the claim amount of female contributors is RM75,360.55 (RM3,768.03 per year).

As the microsimulation is carried out for 20 years, the total QALYs for a full healthy employee is 20 QALYs (20 year of life x 1 utility value for perfect health). However, most of the results fall between 16 and 19 QALYs. In terms of trends, both figures show similar trends of QALYs, except the frequency of QALYs before the peak value, where the value for male is higher than the value for female. Meanwhile, the frequency of female with 20 of QALY value 
is greater than that of the male. In addition, the mean of total QALY for female is higher than that of the male with a mean of 18.13 and 17.63 respectively. The difference, 1.87 QALYs (female) and 2.37 QALYs (male) is interpreted as the quality of life years loss due to sickness (Rowen et al. 2015). The loss refers to time loss as a result of taking care of injured body parts, loss of leisure time with family, waiting time at hospitals, increasing time of resting at home and other related losses due to injury and illness. Compared to the people with perfect health, they might utilize this quality time for their family and themselves or any desired activities.

In general, old people fall ill easily as the immune system weakens over their lifetime. Minimizing the future value of QALY loss is one of the strategies that an employee can do while they are still healthy. For instance, the employee may purchase medical insurance to cover the medical expenses for private hospitals, which can substantially reduce the waiting time compared to waiting time at the public hospitals (MacKinnon 2017). In the case of PPD patients who are unable to continue with their normal job, the burden of the injury and illness can be reduced if they have income replacement protection by purchasing an appropriate insurance.

The larger deviance value of QALY from the total QALYs indicates more burden of sickness to an employee (RiosDiaz et al. 2016). Consequently, from the results it is concluded that male contributors receive more burden of injury and illness than female contributors.

Table 5: The Total Average HCE and Average Yearly HCE for Optimistic, Mean, and Pessimistic Scenarios

\begin{tabular}{cccc}
\hline Gender & Type of & Total & Average \\
Claim & $\begin{array}{c}\text { Average } \\
\text { HCE (RM) }\end{array}$ & $\begin{array}{c}\text { Yearly } \\
\text { HCE (RM) }\end{array}$ \\
\hline Female & Optimistic & 75360.55 & 3768.03 \\
& Mean & 47917.80 & 2395.90 \\
& Pessimistic & 20475.00 & 1023.75 \\
Male & Optimistic & 77929.76 & 3896.50 \\
& Mean & 49537.53 & 2476.90 \\
& Pessimistic & 21095.80 & 1054.80 \\
\hline
\end{tabular}

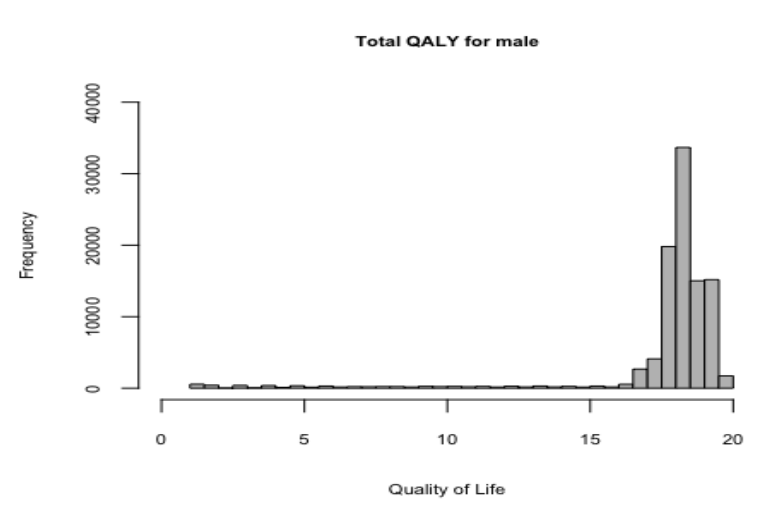

Figure 1: Total QALY for female

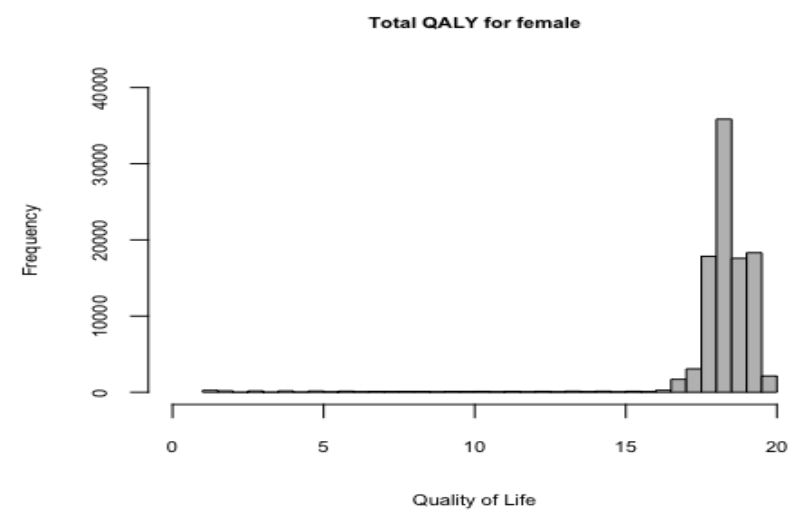

Figure 2: Total QALY for male

\section{CONCLUSION}

This study has examined the discounted health claim expenditure (HCE) among Social Security Organization (SOCSO) contributors in the Employment Injury Scheme (EIS) using microsimulation model. Markov transition probabilities are implemented based on health states, namely healthy (H), temporary disabled (TD), partial permanently disabled (PPD), and death (D). In addition, three claim scenarios are also examined including pessimistic, mean, and optimistic scenarios. The microsimulation model is developed based on Krijkamp et al. (2018) using R statistical package. The microsimulation results indicate that $\mathrm{HCE}$ for male contributors is higher than that of female contributors for every claim scenario. Quality adjusted life year (QALY) is also computed to determine the length and quality of life loss due to injuries and illnesses. The results of QALY show that the male contributors bear more severe injuries and illnesses, compared to the female contributors. For future studies, we plan to examine the effect of treatment intervention on HCE and QALY for EIS contributors. 


\section{ACKNOWLEDGEMENTS}

This paper utilized data from the Malaysian Household Income and Expenses Survey (HEIS) 2014 conducted by the Department of Statistics Malaysia (DOSM). The authors gratefully acknowledge the financial support received in the form of research grants (FRGS/1/2015/SGo4/UKM/O2/2 and AP-2017-011) from the Ministry of Higher Education (MOHE), Malaysia.

\section{REFERENCES}

Ara, R. \& Wailoo, A. 2012, Using health state utility values in models exploring the cost-effectiveness of health technologies. Value in Health, 15(6), 971-974.

Bank Negara Malaysia. 2018, Retrieved from http://www.bnm.gov.my/index.php?ch=statistics\&pg=s tats_interestrates_c\&type $=3$

Hennessy, D. A., Flanagan, W. M., Tanuseputro, P., Bennett, C., Tuna, M., Kopec, J., Manuel, D. G. 2015, The Population Health Model (POHEM): An overview of rationale, methods and applications. Population Health Metrics, 13(1), 1-12.

Krijkamp, E. M., Alarid-Escudero, F., Enns, E. A., Jalal, H. J., Hunink, M. G. M., \& Pechlivanoglou, P. 2018, Microsimulation modeling for health decision sciences using R: A tutorial. Medical Decision Making, 38(3), $400-422$.

MacKinnon, J. C. 2017, Wait times in Canada. Healthcare Management Forum, 30(4), 190-192.

Mather, R. C., Koenig, L., Kocher, M. S., Dall, T. M., Gallo, P., Scott, D. J., Spindler, K. P. 2013, Societal and Economic Impact of Anterior Cruciate Ligament Tears. The Journal of Bone and Joint Surgery-American Volume, 95(19), 1751-1759.

Rios-Diaz, A. J., Lam, J., Ramos, M. S., Moscoso, A. V., Vaughn, P., Zogg, C. K., \& Caterson, E. J. 2016, Global patterns of QALY and DALY use in surgical cost-utility analyses: A systematic review. PLoS ONE, 11(2).

Rongen, J. J., Govers, T. M., Buma, P., Grutters, J. P. C., \& Hannink, G. 2016, Societal and economic effect of Meniscus Scaffold Procedures for irreparable Meniscus injuries. The American Journal of Sports Medicine, 44(7), 1724-1734.
Roudijk, B., Donders, A. R. T., \& Stalmeier, P. F. M. 2018, Setting dead at zero: Applying scale properties to the QALY model. Medical Decision Making, 1-8.

Rowen, D., Brazier, J., Mukuria, C., Keetharuth, A., Hole, A. R., Tsuchiya, A., ... Shackley, P. 2015, Eliciting societal preferences for weighting QALYs for burden of illness and end of life. Medical Decision Making, 1-13.

Samsuddin, S., \& Ismail, N. 2018, Corak hilang upaya dalam kalangan pekerja di Malaysia: Kajian kes bagi pencarum PERKESO. Jurnal Sains Kesihatan Malaysia, 16(1), 87-94.

Taş, Ü., Verhagen, A. P., Bierma-Zeinstra, S. M. A., Hofman, A., Pols, H. A. P., \& Koes, B. W. 2012, Course and prognostic factors of disability in communitydwelling older people with mild disability: The Rotterdam study. Australasian Journal on Ageing, 31(1), 28-33.

Social Security Organisation Malaysia. 2018, Retrieved from

https://www.perkeso.gov.my/index.php/en/socialsecurity-protection-scheme/employment-injury-scheme Van Ballegooijen, M., Rutter, C. M., Knudsen, A. B., Zauber, A. G., Savarino, J. E., Lansdorp-Vogelaar, I., ... Kuntz, K. M. 2011, Clarifying differences in natural history between models of screening: The case of colorectal cancer. Medical Decision Making, 31(4), 540-549.

Whitehead, S. J., \& Ali, S. 2010, Health outcomes in economic evaluation: The QALY and utilities. British Medical Bulletin, 96(1), 5-21.

Zainuddin, J. 2014, Malaysia National Health Accounts. 